\title{
Adoption of the More-Than-Voice Technology at the Bottom of the Pyramid: Evidence from India
}

\author{
Muhammad Muazzem Hossain ${ }^{1}$ \\ ${ }^{I}$ Associate Professor, College of Business Administration, Prince Mohammad Bin Fahd University \\ P.O. Box 1664, Al Khobar 31952, Kingdom of Saudi Arabia.
}

ORCID: 0000-0002-8878-3075

\begin{abstract}
In today's digital world, mobile phones have become indispensable, being considered the fifth necessity in addition to food, clothing, shelter, and education. Mobile phone subscriptions surpassed the world population in 2016. There is a plethora of uses of mobile phones that include the more-thanvoice (MTV) technology such as messaging, mobile banking, bill payments, etc. The MTV technology has become ubiquitous all over the world. However, there is a paucity of evidence of adequate research regarding the consumer acceptance of the MTV technology by the bottom of the pyramid (BoP) in the developing countries. This study examines the factors influencing the adoption of the MTV technology by the BoP in India. The findings suggest that there are five significant predictors of the acceptance of MTV technology in India. These factors include the perceived usefulness, perceived ease of use, perceived social influence, perceived value, and perceived propensity to use the MTV technology. The results indicate that there are positive relationships between these factors and the acceptance of the MTV technology by the BoP in India. The study also proposed that perceived acumen to use and perceived facilitating conditions have a positive influence on the acceptance of the MTV technology. However, the findings show a lack of such evidence in India.
\end{abstract}

Keywords: More-than-voice Technology, MTV Services, Bottom of Pyramid, Technology Adoption, Consumer Acceptance, COVID-19

\section{INTRODUCTION}

The use of mobile phones has become not only ubiquitous but also indispensable all over the world. Mobile phones are no longer considered a symbol of social status, rather have become the fifth necessity in addition to food, clothing, shelter and education [1]. According to the World Bank data (Fig. 1), the number of mobile subscriptions has seen a steep increase over the past decade and surpassed the world population in 2016. Gupta [1] posits that the actual number of mobile phones will be higher than that of subscriptions as many families with one subscription may own multiple mobile phones for different family members. The use of this vast number of mobile phones spans beyond their primary purpose of voice calls and encompasses the more-than-voice (MTV) technology. The term MTV technology refers to the "direct or indirect usage of mobile phones in services other than voice calls" [2] and encompasses services such as "messaging, mobile banking, bill payments, updates on social media, watching television, playing games, listening to music, browsing the Web, etc." [2]. As the MTV services are the embodiment of MTV technology, this study uses the terms "MTV services" and "MTV technology" synonymously.

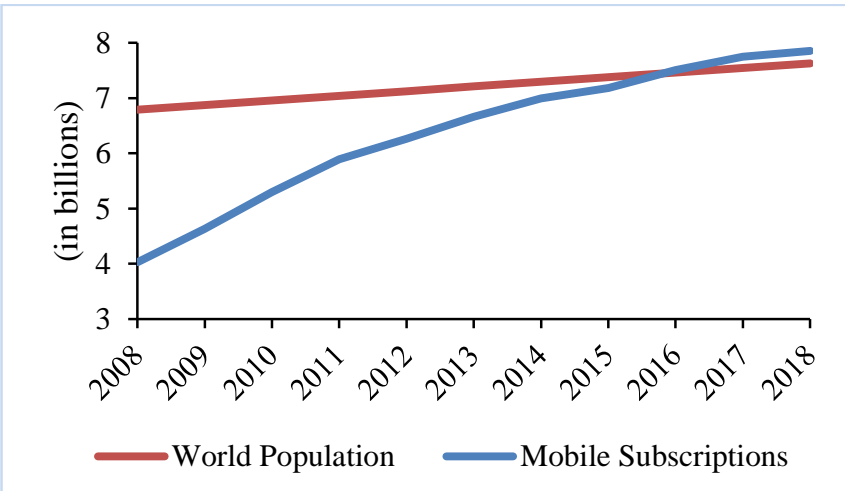

Fig. 1. Mobile Subscriptions versus World Population

There is a plethora of usage of MTV services around the globe. Examples of traditional MTV services abound. For instance, M-Pesa in Africa, IMPS (Inter-Bank Mobile Payment Service) in India and bKash in Bangladesh have drastically changed the landscape of banking beyond the traditional brick-and-mortar banking concept [3] [4]. Eighty to nine five percent of the population of Kenya, Mexico and Indonesia use text messaging services [5]. Wireless telecom providers in Bangladesh and the Middle East promote their service plans and promotions through mobile advertising. MTV technology has made several other technologies obsolete. Some examples of these technologies include the frequency modulation (FM) radio, typewriters, pagers and beepers, personal digital assistants, etc.

The recent trends in MTV technology stemmed from the advancement of information and telecommunication technology (ICT) and the integration of multitude of features into mobile phones. With increasing access to mobile internet - over 3.5 billion people in 2018 [6] - and upgrading of mobile phones with new software features and improved hardware technologies such as camera, Bluetooth, near-field communication (NFC), etc., MTV services are becoming more commonplace and indispensable in both normalcies and emergencies. The integration of the global position system (GPS) and the general packet radio system (GPRS) in mobile 
phones helps us find directions, browse the internet, communicate in the social media or via email, report a crime or savage a crime being committed, or capture and broadcast natural disasters on the go [1]. Currently, MTV technology is playing a vital role in the coronavirus disease 2019 (COVID19) pandemic. For example, Hong Kong, Singapore, Germany, the UK, Australia, and South Korea are utilizing contract tracing, an MTV service, to trace and slow down the spread of COVID-19 infectious outbreaks [7]. The Ministry of Health $(\mathrm{MOH})$ of Saudi Arabia is using the mass text-messaging and WhatsApp services as parts of Kingdom's effort to manage the COVID-19 pandemic [8].

There is a widespread use and an increasing growth of MTV services across the globe. Various studies have been conducted regarding the penetration, challenges, concerns and benefits of MTV services in both developed and developing countries [6] [9]. However, researches are scant on how MTV services are adopted by consumers at the bottom of the pyramid (BoP) in developing nations. The concept of BoP was coined by Prahalad and Hart [10] to represent a socio-economic group of people who earn less than two dollars a day. Prahalad and Hart [10] argued that there were 4 billion people around the world that represented a vibrant consumer market. To date, the BoP continues to represent a vibrant consumer market for MTV services due to the widespread use of mobile phones among the world's poor, enabling companies to develop and deliver important MTV services [11]. Thus, an understanding of what factors affect the adoption of MTV services by the BoP will help organizations devise strategies to implement these services. This study develops a theoretical model that examines the factors affecting the acceptance of MTV services by the BoP and provides empirical evidence from India.

The rest of the paper is organized as follows. The theoretical foundation to the study is expounded in Section II followed by expositions of research hypotheses in Section III, methodology for the study in Section IV, findings and analysis in Section V, and conclusion on the major findings and their implications in Section VI.

\section{THEORETICAL BACKGROUND}

This study draws from the two intermingling streams of literature, namely, information technology (IT), and information and telecommunication technology (ICT). The term IT refers to any form of technology for handling information [12] and integrates information processing and communication technologies that are based on computers with stored memory [13]. Hossain and Jamil [2] posit that "MTV services involve a blend of ICT and IT technologies in that they are consumed using wireless telecommunications and cellular phone technologies."

A review of the relevant ICT literature suggests two important aspects of understanding the use of mobile phones within the telecommunication infrastructure. First, the extant ICT literature provides substantial evidence on the role of demographic variables such as income and education in explaining the MTV services. Studies have found significant positive relationships of these variables with the use of computer and internet but lack evidence of any significant influence of them on the use of mobile phones in developing countries [14] [15]. Second, the ICT literature adapted from the IT literature constructs such as usefulness, ease of use, price value, social influence and facilitating conditions, among others, that can explain the adoption of MTV services. Two widely used IT models that have lent heavily to the ICT literature are the technology acceptance model (TAM) [16] and the unified theory of acceptance and use of technology (UTAUT) [17]. Both TAM and UTAUT can be applied across technologies, people, settings, and times to explain technology acceptance [18]. Numerous studies have utilized TAM as the underlying theoretical model. Some examples of the use of TAM is evident in the adoption of mobile electronic medical record systems [18], RFID technology [19], mobile commerce [20], mobile chat [21], etc. Similarly, there are a plethora of uses of UTAUT in the arena of IT and ICT literature. UTAUT has been used as an underlying basis to explain the social media acceptance in non-profit organizations and public relations [22] online social support in using instant messaging [23], mobile commerce acceptance [24], mobile banking acceptance [25], short messaging system [26], varying frequencies of computer use and differences in information and communication technology skills [27], etc. in both developed and developing nations.

The extant literature reveals that TAM and UTAUT have laid the foundation for numerous studies - independently as well as jointly. Hossain and Jamil [2] posit that each of TAM and UTAUT has shortcomings in explaining the adoption of MTV services that the other can complement. For instance, TAM cannot be used to explain the influence of volitional, situational and social conditions in IT and ICT usage as these factors are not included in the model [28]. Hossain and Jamil [2] developed the consumer acceptance of MTV technology services (CAMTVT) by incorporating the necessary constructs from TAM and UTAUT. Gleaning from both TAM and UTAUT, this study extends the CAMTVT model and tests it in the context of India.

\section{RESEARCH MODEL AND HYPOTHESES}

Based on the theoretical foundation, this study posits that consumer acceptance of MTV services is a function of perceived usefulness, perceived ease of use, perceived social influence, perceived value, perceived propensity to use, perceived acumen to use and perceived facilitating conditions. That is,

\begin{tabular}{|c|c|c|c|}
\hline Where: & ITU & $=$ & Intention to use MTV services \\
\hline & PU & $=$ & Perceived usefulness \\
\hline & PEU & $=$ & Perceived ease of use \\
\hline & PSI & $=$ & Perceived social influence \\
\hline & PV & $=$ & Perceived value \\
\hline & PPU & $=$ & Perceived propensity to use \\
\hline & PAU & $=$ & Perceived acumen to use \\
\hline and, & PFC & $=$ & Perceived facilitating conditions \\
\hline
\end{tabular}


The proposed research model is presented in Fig. 2.

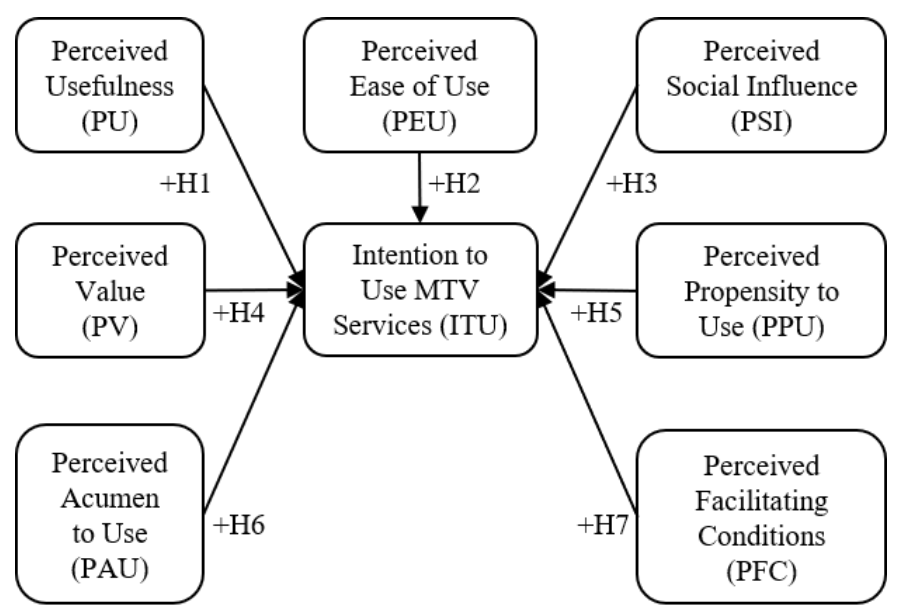

Fig. 2. Research Model for Adoption of MTV Technology

Table 1 provides a brief description of the model constructs. The summary descriptions of the constructs have been adapted from [2] and [19].

Table 1. Description of the Model Constructs

\begin{tabular}{ll}
\hline Construct & Description \\
\hline Intention to use & The extent to which the user would \\
(ITU) & reuse MTV services in future [2]
\end{tabular}

Perceived usefulness (PU)

The extent to which consumers believe that using MTV services performs a task or fulfils a requirement in a given time and place [19]

Perceived ease The extent to which consumers find the of use (PEU) use of MTV services comfortable and free of effort [19]

Perceived social The extent to which consumers believe influence (PSI) that their peers use and approve their use of MTV services [2]

Perceived value The extent to which consumers believe (PV) that the MTV services are reasonably priced and that the use of these services is worth the price paid for [2]

Perceived The extent to which consumers believe propensity to use that they have the control over and the (PPU) necessary knowledge to use MTV services [2]

Perceived acumen to use (PAU)

The extent to which consumers believe that they have the knowledge and ability to accurately use the MTV services

Perceived facilitating conditions (PFC)

The extent to which consumers believe that they will have a helping hand to use MTV services when they need it [2]

The proposed research model has one dependent variable and seven independent variables. The models that underlie this model posit that all independent measures (i.e., PU, PEU, PSI, PV, PPU, PAU, PFC) positively influence the dependent measure (i.e., ITU). Based on the theoretical underpinnings, we propose the following hypotheses:

H1: Perceived usefulness positively influences the intention to use MTV services.

H2: Perceived ease of use positively influences the intention to use MTV services.

H3: Perceived social influence positively influences the intention to use MTV services.

H4: Perceived value influence positively influences the intention to use MTV services.

H5: Perceived propensity to use positively influences the intention to use MTV services.

H6: Perceived acumen to use positively influences the intention to use MTV services.

H7: Perceived facilitating conditions positively influence the intention to use MTV services.

\section{METHODOLOGY}

To test the proposed model, this study obtained data from the Teleuse@BOP4 study. The Teleuse@BOP4 study was aimed at understanding the livelihood and productivity related uses of mobile telecommunications (i.e., MTV services) at the bottom of the pyramid (BoP). The study was carried out by LIRNEasia, a pro-poor and pro-market think tank, that conducts research on ICT industries and related sectors. In the Teleuse@BOP4 study, LIRNEasia administered a face-to-face survey on the use of mobile phones among the BoP consumers in Bangladesh, India, Pakistan, Java (Indonesia), Sri Lanka and Thailand. This study used the Teleuse@BOP4 study data obtained from India. The Teleuse@BOP4 study conducted 760 complete surveys on the acceptance of MTV services by the BoP in India.

Using the secondary data obtained from the Teleuse@BOP4 study provides several benefits. First, many researchers have utilized the Teleuse@BOP4 dataset in their studies due to its well-accepted reliability and validity [29] [30] [31] [32]. Second, using this dataset has saved time and money. Finally, a review of the publications based on the Teleuse@BOP4 data reveals that none of them have used the data for the same purpose and context as that of the current study. Thus, the data is deemed appropriate for use in testing the proposed research model.

\section{ANALYSES AND RESULTS}

SPSS was used to analyze the data. The analyses included the factor analyses, reliability and validity analyses, and multiple regression analyses. The results of these analyses are presented below.

\section{V.I Factor Analyses}

Two separate factor analyses were conducted - one to identify the relevant factors for the independent measures and the other for the dependent measure. Seven factors were extracted from the independent measures, corresponding to constructs such as perceived usefulness (PU), perceived ease of use (PEU), 
International Journal of Engineering Research and Technology. ISSN 0974-3154, Volume 13, Number 6 (2020), pp. 1179-1186

(C) International Research Publication House. https://dx.doi.org/10.37624/IJERT/13.6.2020.1179-1186

perceived social influence (PSI), perceived value (PV), perceived propensity to use (PPU), perceived acumen to use (PAU) and perceived facilitating conditions (PFC). One factor was extracted from the dependent measures, corresponding to

Table 2. Scale Items - Independent Variables intention to use MTV technology (ITU). Table 2 and Table 3 provide the results of the factor analyses for independent and dependent measures, respectively.

$\begin{array}{llllll}\text { PU PEU } & \text { PSI } & \text { PV } & \text { PPU } & \text { PAU } & \text { PFC }\end{array}$

\section{Perceived usefulness (PU)}

PU2: Using ___ increases my chances of achieving things that are important to me

PU3: Using __ helps me accomplish things more quickly

PU1: I find __ to be useful in my life

0.801

0.704

0.663

\section{Perceived ease of use (PEU)}

PEU2: I think learning how to use ___ is easy to me

PEU3: My interaction with ___ is clear and understandable PEU1: I find to be easy to use

0.877

0.695

0.544

\section{Perceived social influence (PSI)}

PSI3: I use ___ because I want to use the same service people around me use

PSI4: I use __ because it is common to use it in my community

PSI2: People who influence my behaviors think I should use

\section{Perceived value (PV)}

PV1: I think is reasonably priced

PV2: I think offers values for money

0.794

\section{Perceived Propensity to Use (PPU)}

PPU3: Using ___ is a good idea

PPU2: Based on my experience with , I know it is trustworthy

PPU1: Based on my experience with it provides good service , I know

PPU4: Using is a wise idea

\section{Perceived acumen to use (PAU)}

PAU2: Using ___ is entirely within my control

PAU1: I have the knowledge and ability necessary to use

\section{Perceived facilitating condition (PFC)}

PFC1: When I have problems in using from my friends/family members I can get help PFC2: When I have problems in using ___. I can get help from the service providers or experts

Percentage of variance $($ total $=70.88 \%)$

Mean

Std deviation

Cronbach's alpha

Note: Scale anchor: 1 = strongly disagree; 5 = strongly agree 
Table 3. Scale Items - Dependent Variables

\begin{tabular}{|c|c|}
\hline & ITU \\
\hline \multicolumn{2}{|l|}{ Intention to use MTV (ITU) } \\
\hline $\begin{array}{l}\text { ITU3: I expect that I would use } \\
\text { frequently in future }\end{array}$ & 0.874 \\
\hline ITU2: I intend to use ___ in future & 0.807 \\
\hline ITU1: I like the idea of using ___. & 0.729 \\
\hline Mean & 4.725 \\
\hline Standard Deviation & 0.488 \\
\hline Cronbach's alpha & 0.723 \\
\hline
\end{tabular}

Scale anchor: 1 = strongly disagree; 5 = strongly agree

\section{V.II Reliability and Validity Analyses}

Cronbach's alpha is used to test for the internal consistency (i.e., the reliability) of the measures. A Cronbach's alpha value of 0.65 or higher [33] indicates that the factors have an adequate level of internal consistency. The Cronbach's alpha values for independent and dependent variables are shown in Table 2 and Table 3, respectively. These values range from 0.653 to 0.773 , indicating that all factors have adequate reliability.

The factors were tested for the convergent validity and discriminant validity. The item-to-total correlations were used to test for the convergent validity and the inter-factor correlations for the discriminant validity. Factors have adequate convergent validity if all item-to-total correlations equal or exceed the recommended value of 0.40 [34]. For a factor to have adequate discriminant validity, its Cronbach's alpha score must exceed its inter-factor correlations with others [35] [36]. The item-to-total correlations are shown in Table 4 and the inter-factor correlations in Table 5. As Table 4 and Table 5 show, the measures have adequate level of both convergent and discriminant validities.

Table 4. Scale Reliability and Convergent Validity

\begin{tabular}{|c|c|}
\hline Scale Items & $\begin{array}{c}\text { Corrected } \\
\text { Item-Total } \\
\text { Correlation } \\
\end{array}$ \\
\hline \multicolumn{2}{|l|}{ Perceived usefulness (PU) } \\
\hline $\begin{array}{l}\text { PU2: Using __ increases my chances of } \\
\text { achieving things that are important to me }\end{array}$ & 0.659 \\
\hline $\begin{array}{l}\text { more quickly } \\
\text { mosing }\end{array}$ & 0.616 \\
\hline PU1: I find ___ to be useful in my life & 0.559 \\
\hline \multicolumn{2}{|l|}{ Perceived ease of use (PEU) } \\
\hline $\begin{array}{l}\text { PEU2: I think learning how to use ___ is easy } \\
\text { to me }\end{array}$ & 0.568 \\
\hline $\begin{array}{l}\text { PEU3: My interaction with ___ is clear and } \\
\text { understandable }\end{array}$ & 0.585 \\
\hline PEU1: I find ___ to be easy to use & 0.537 \\
\hline \multicolumn{2}{|l|}{ Perceived social influence (PSI) } \\
\hline $\begin{array}{l}\text { PSI3: I use __ because I want to use the } \\
\text { same service people around me use }\end{array}$ & 0.504 \\
\hline
\end{tabular}

PSI4: I use because it is common to use it in my community

PSI2: People who influence my behaviors think I should use

\section{Perceived value (PV)}

PV1: I think __ is reasonably priced

PV2: I think offers values for money

\section{Perceived Propensity to Use (PPU)}

PPU3: Using ___ is a good idea

PPU2: Based on my experience with I know it is trustworthy

PPU1: Based on my experience with , I know it provides good service

PPU4: Using is a wise idea

\section{Perceived acumen to use (PAU)}

PAU2: Using is entirely within my control

PAU1: I have the knowledge and ability necessary to use

\section{Perceived facilitating condition (PFC)}

PFC1: When I have problems in using can get help from my friends/family members

PFC2: When I have problems in using __. I can get help from the service providers or experts

Table 5. Inter-Factor Correlations

\begin{tabular}{cccccccc}
\hline & PU & PEU & PSI & PV & PPU & PAU & PFC \\
\hline PU & $\mathbf{0 . 7 7 3}$ & & & & & & \\
PEU & .540 & $\mathbf{0 . 7 3 9}$ & & & & & \\
PSI & .467 & .439 & $\mathbf{0 . 6 5 5}$ & & & & \\
PV & .428 & .436 & .243 & $\mathbf{0 . 7 0 3}$ & & & \\
PPU & .508 & .444 & .415 & .382 & $\mathbf{0 . 7 2 5}$ & & \\
PAU & .476 & .465 & .334 & .433 & .411 & $\mathbf{0 . 6 5 4}$ & \\
PFC & .216 & .179 & .133 & .229 & .234 & .250 & $\mathbf{0 . 6 5 3}$ \\
\hline Note: The diagonal values are alpha scores.
\end{tabular}

Note: The diagonal values are alpha scores.

\section{V.III Regression Analysis}

The proposed research model presented in Figure 1 has seven independent variables predicting the dependent variable and thereby posits seven hypotheses. Multiple regression analysis was conducted to test these hypotheses. We used summated scores of the respective factors to obtain the scores for both dependent and independent measures. For the regression analysis, PU, PEU, PSI, PAU, PV and PFC were the independent variables predicting the dependent variable, ITU. The results of the regression analysis are presented in Table 6 . 
International Journal of Engineering Research and Technology. ISSN 0974-3154, Volume 13, Number 6 (2020), pp. $1179-1186$

(C) International Research Publication House. https://dx.doi.org/10.37624/IJERT/13.6.2020.1179-1186

Table 6. Regression Analysis Predicting Intention to Use MTV Technology

\begin{tabular}{lcccccccc}
\hline Predictors & $\begin{array}{c}\text { Unstd. Beta } \\
\text { Coeff. }\end{array}$ & $\begin{array}{c}\text { Std. Beta } \\
\text { Coeff. }\end{array}$ & t-Stat & p-Value & VIF & Hypothesis & $\begin{array}{c}\text { Hypothesized } \\
\text { Effect }\end{array}$ & Supported? \\
\hline PU & 0.123 & 0.129 & 3.314 & 0.001 & 1.506 & $\mathrm{H} 1$ & + & Yes \\
PEU & 0.133 & 0.139 & 3.659 & 0.000 & 1.431 & $\mathrm{H} 2$ & + & Yes \\
PSI & 0.066 & 0.084 & 2.309 & 0.021 & 1.326 & $\mathrm{H} 3$ & + & Yes \\
PV & 0.062 & 0.080 & 2.312 & 0.021 & 1.203 & $\mathrm{H} 4$ & + & Yes \\
PPU & 0.340 & 0.319 & 8.467 & 0.000 & 1.418 & $\mathrm{H} 5$ & + & Yes \\
PAU & 0.017 & 0.023 & 0.627 & 0.531 & 1.352 & $\mathrm{H} 6$ & + & No \\
PFC & -0.100 & -0.030 & -0.937 & 0.349 & 1.022 & $\mathrm{H} 7$ & - & No \\
& & & & & & & & \\
$\mathrm{R}$ & $=0.679$ & & & & & & & \\
$\mathrm{R}^{2}$ & $=0.462$ & & & & & & & \\
Adjusted $\mathrm{R}^{2}$ & $=0.457$ & & & & & & & \\
\hline
\end{tabular}

The runs test, Levene's test and Kolmogorov-Smirnov test were conducted to check for randomness, constancy of variance, and normality, respectively. These tests show no evidence of violation of the assumptions underlying multiple regression analysis. We used the VIFs and condition indices to measure multicollinearity. As the VIFs and condition indexes were within acceptable levels (VIFs $<4.00$ and condition indexes $<30.00$ ), there was no evidence of multicollinearity.

The results of multiple regression analysis presented in Table 5 show support for five hypotheses ( $\mathrm{H} 1, \mathrm{H} 2, \mathrm{H} 3, \mathrm{H} 4$ and $\mathrm{H} 5)$. The findings indicate that PU, PEU, PSI, PV, and PPU are significant predictors of ITU. Thus, perceived usefulness, perceived ease of use, perceived social influence, perceived value, and perceived propensity to use MTV services play significant role in predicting the intention to use these services. The results also show that PAU and PFC are insignificant predictors of ITU, suggesting that perceived acumen of use and perceived facilitating condition do not affect the intention to use MTV technology in the presence of other independent variables.

\section{CONCLUSION}

This study investigated the factors affecting consumer acceptance of MTV services at the Bottom of Pyramid in India. The research model proposed that intention to use MTV services was influenced by perceived usefulness, perceived ease of use, perceived social influence, perceived acumen to use, perceived value, and perceived facilitating condition. The findings suggest that perceived usefulness, perceived ease of use, perceived social influence, perceived value, and perceived propensity to use are the significant predictors of the acceptance of MTV technology by the BoP in India. The results also indicate that there are positive relationships between these factors and the acceptance of the MTV technology. This implies that the more favourable the consumer perceptions are regarding the usefulness, ease of use, social influence, value, and propensity to use, the greater the likelihood that consumers will accept the MTV technology. The study also proposed that perceived acumen to use and perceived facilitating conditions have a positive influence on the acceptance of the MTV technology. However, the findings show a lack of such evidence in India.

In comparison with prior literature, the findings demonstrate a mixed effect. Consistent with Hossain and Jamil [2], this study provides an impetus that the MTV service providers should make their MTV technology more useful, easy to use, socialoriented and value-generating. In addition, this study extended the CAMTVT model [2] by adding an independent construct, namely, propensity to use the MTV technology and found this to be a significant predictor of the MTV technology. This finding implies that the MTV service providers should promote the trustworthiness, goodness, and wisdom of using the MTV technology. Yet, another consistent finding with [2] holds facilitating conditions play no significant role in explaining the intention to use the MTV technology. That is, consumers in the developing countries perceive that their intention to adopt the MTV technology will not be affected by the availability of any form of facilitation of, or support for use from their friends, family members and/or service providers. This observation bears a practical implication in that as it contradicts the notion that "an organizational and technical infrastructure exists to support use of the system" [37]. These findings are also in line with other considerable research on IT acceptance such as [38] [39]. However, contrary to Hossain and Jamil [2], this study found that perceived acumen to use played no significant role in predicting the MTV technology. This finding is important due to two-fold reasons. First, there exists a varying understanding of the concept of acumen to use in different developing countries. Second, this construct calls for further investigation in the context of the MTV technology adoption in the developing nations.

In conclusion, this study provides insights that have both practical and academic implications in MTV technology literature, in particular, and ICT literature, in general. The important practical implication of this study is that it sheds light on what the MTV technology service providers emphasize in the developing nations to gain the acceptability of the 
technology by the bottom of the pyramid. On the other hand, the important academic implication of this study is that it provides a theoretical framework that can be further explored in other developed and developing regions and beyond the context of the bottom of the pyramid.

\section{REFERENCES}

[1] Gupta GK. Ubiquitous Mobile Phones Are Becoming Indispensable. ACM Inroads. 2011;2(2):32-33.

[2] Hossain MM, Jamil R. Consumer Acceptance of MoreThan-Voice (MTV) Services: Evidence from the Bottom of Pyramid in Bangladesh. Journal of Developing Areas. 2015;49(5):25-39.

[3] Govindarajan V. Developing Countries Are Revolutionizing Mobile Banking. Harvard Business Review. 2012(April 30). Accessed on August 14, 2014 from http://blogs.hbr.org/2012/04/innovations-inmobile-banking/

[4] Ellis E. bKash Builds a Payments System for the Future. AsiaMoney. 2018(March 27). Accessed on April 30, 2020 from https://www.euromoney.com/article/b17dwmpny7nzd w/bkash-builds-a-payments-system-for-the-future

[5] Mlot S. Infographic: Mobile Use in Developing Nations Skyrockets. PCMag. 2012 (July 18). Accessed on August 13, 2014 from http://www.pcmag.com/article2/0,2817,2407335,00.asp

[6] Bahia K. Suardi S. The State of Mobile Internet Connectivity 2019. GSMA Intelligence. 2019(July). Accessed on May 10, 2020 from https:/www.gsma.com/mobilefordevelopment/wpcontent/uploads/2019/07/GSMA-State-of-MobileInternet-Connectivity-Report-2019.pdf

[7] Lawrie E. Coronavirus: How Does Contact Tracing Work and Is My Data Safe? BBC News. 2020(6 May). Accessed on May 10, 2020 from https://www.bbc.com/news/explainers-52442754

[8] Arabnews. Saudi Health Ministry Launches WhatsApp Service in COVID-19 Fight. 2020(10 May). Accessed on May 10, 2020 from https://www.arabnews.com/node/1672041/saudi-arabia

[9] Pew Research Center, March 2019, "Mobile Connectivity in Emerging Economies."

[10] Prahalad CK. Hart SL. The fortune at the Bottom of the Pyramid. Strategy+Business. 2006;26:1-14.

[11] Prahalad D. The New Fortune at the Bottom of the Pyramid. Strategy+Business. 2019;94(Spring):1-13.

[12] Gruer M. Information Technology. In Smelser NJ. Baltes PB. (Eds.). International Encyclopedia of the Social and Behavioral Sciences. 2001;7473-7476.

[13] Terashima N. Intelligent Communication Systems. In Smelser NJ. Baltes PB. (Eds.). International
Encyclopedia of the Social and Behavioral Sciences. 2002;1-6.

[14] Rad TS. Kurt Ş. Polatöz S. Use of Information and Communication Technologies in Rural Mersin (Turkey): Prospects for Rural Development. Mersin Kırsalında Sürdürülebilir Kırsal Kalkınmada Bilgi ve İletişim Teknolojilerinden Yararlanma. 2013;10(3):97106.

[15] Baliamoune-Lutz M. An Analysis of the Determinants and Effects of ICT Diffusion in Developing Countries. Information Technology for Development. 2003;10(3):151-169.

[16] Davis FD. Perceived Usefulness, Perceived Ease of Use, and User Acceptance of Information Technology. MIS Quarterly. 1989;13(3):319-340.

[17] Venkatesh V. Morris MG. Davis GB. Davis FD. User Acceptance of Information Technology: Toward a Unified View. MIS Quarterly. 2003;27(3):425-478.

[18] Kuo K-M. Liu C-F. Ma C-C. An investigation of the Effect of Nurses' Technology Readiness on the Acceptance of Mobile Electronic Medical Record Systems. BMC Medical Informatics and Decision Making. 2013;13(88):1-14.

[19] Hossain MM. Prybutok VR. Consumer Acceptance of RFID Technology: An Exploratory Study. IEEE Transactions on Engineering Management. 2008;55(2):316-328.

[20] Cyr D. Head M. Ivanov A. Design Aesthetics Leading to M-loyalty in Mobile Commerce. Information \& Management. 2006;43(8):950-963.

[21] Nysveen H. Pedersen PE. Thorbjornsen H. Explaining Intention to Use Mobile Chat Services: Moderating Effects of Gender. Journal of Consumer Marketing. 2005;22(5): 247-256.

[22] Curtis L. Edwards C. Fraser KL. Gudelsky S. Holmquist J. Thornton K. Sweetser KD. Adoption of Social Media for Public Relations by Nonprofit Organizations. Public Relations Review. 2010;36(1): 90-92.

[23] Lin C-P. Anol B. Learning Online Social Support: An Investigation of Network Information Technology Based on UTAUT. Cyberpsychology \& Behavior: The Impact of the Internet, Multimedia and Virtual Reality on Behavior and Society. 2008;11(3): 268-272.

[24] Min Q. Ji S. Qu G. Mobile Commerce User Acceptance Study in China: A Revised UTAUT Model. Tsinghua Science \& Technology. 2008;13(3): 257-264.

[25] Zhou T. Lu Y. Wang B. Integrating TTF and UTAUT to Explain Mobile Banking User Adoption. Computers in Human Behavior. 2010;26(4):760-767.

[26] Carlsson C. Carlsson J. Hyvonen K. Puhakainen J. Walden P. Adoption of Mobile Devices/Services: Searching for Answers with the UTAUT. Proceedings of the 39th Annual Hawaii International Conference on System Sciences (HICSS 2006). 2006;6:132a-132a. 
[27] Verhoeven JC. Heerwegh D. de Wit K. Information and Communication Technologies in the Life of University Freshmen: An Analysis of Change. Computers \& Education. 2010;55(1):53-66.

[28] Abbasi MS. Chandio FH. Soomro AF. Shah F. Social Influence, Voluntariness, Experience and the Internet Acceptance: An Extension of Technology Acceptance Model Within a South-Asian Country Context. Journal of Enterprise Information Management. 2011;24(1):3052.

[29] Agüero A. de Silva H. Kang J. Bottom of the Pyramid Expenditure Patterns on Mobile Services in Selected Emerging Asian Countries. Information Technologies \& International Development. 2011;7(3):19-32.

[30] Lokanathan S. Nilusha K. Smallholders and Microenterprises in Agriculture: Information Needs and Communication Patterns. ME Report. 2012, Colombo, Sri Lanka: LIRNEasia, pp. 1-48.

[31] Zainudeen A. Ratnadiwakara D. Are the Poor Stuck in Voice? Conditions for Adoption of More-than-voice Mobile Services. Information Technologies \& International Development. 2011;7(3):45-59.

[32] Zainudeen A. Samarajiva R. Sivapragasam N. CellBazaar: Enabling M-Commerce in Bangladesh. Information Technologies \& International Development. 2011;7(3):61-76.

[33] Nunnally JC. Psychometric theory. United States: McGraw-Hill, 1978.

[34] Jayanti RK. Burns AC. The Antecedents of Preventive Health Care Behavior: An Empirical Study. Journal of the Academy of Marketing Science. 1998;26(1):6-15.

[35] Gaski JF. Nevin JR. The Differential Effects of Exercised and Unexercised Power Sources in a Marketing Channel. Journal of Marketing Research. 1985;22(2):130-142.

[36] Hossain MM. Understanding Turnover Intention: Country of Job as a Moderator. International Journal of Innovation, Creativity and Change. 2019;9(9):9-23.

[37] Venkatesh V. Thong JY. Xu X. Consumer Acceptance and Use of Information Technology: Extending the Unified Theory of Acceptance and Use of Technology. MIS Quarterly. 2012;26(1):157-178.

[38] [37] Venkatesh V. Brown SA. Maruping LM. Bala H. Predicting different conceptualizations of system USE: The competing roles of behavioral intention, facilitating conditions, and behavioral expectation. Management Information Systems. 2008;32(3):483-502.

[39] Zhang J. Mao E. Understanding the acceptance of mobile SMS advertising among young Chinese consumers. Psychology \& Marketing. 2008;25(8):787805. 